ESTUDIOS 



\title{
«LIBRE» DESIGNACIÓN Y «LIBRE»CESE EN LA FUNCIÓN PÚBLICA: LOS LÍMITES DE LA DISCRECIONALIDAD
}

\author{
MIGUEL SÁNCHEZ MORÓN \\ Universidad de Alcalá
}

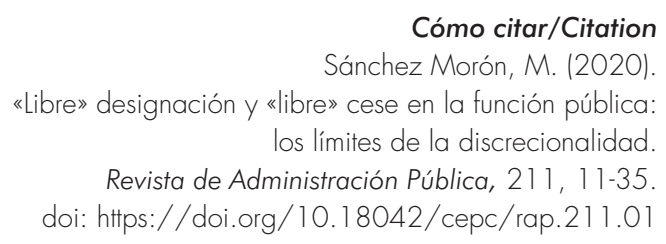

Resumen

Tradicionalmente se venía entendiendo, tanto por el legislador como por los tribunales, que las autoridades competentes gozaban de una muy amplia discrecionalidad para decidir sobre el nombramiento y cese de los titulares de los numerosos puestos de trabajo reservados a funcionarios públicos que se cubren por el sistema de libre designación. La jurisprudencia reciente del Tribunal Supremo ha cambiado radicalmente esa concepción y exige que tales decisiones sean motivadas estrictamente sobre la base de los méritos e idoneidad de los funcionarios interesados. El presente artículo estudia esta evolución y sus posibles consecuencias. 


\section{Palabras clave}

Función pública; nombramientos; discrecionalidad administrativa; control judicial; motivación.

\section{Abstract}

Traditionally Spanish laws and courts granted broad discretionary powers to the public authorities to appoint and dismiss the high officials of their Departments, according to the so-called «free appointment» procedure. Recent jurisprudence has radically changed the rules and now requires strict motivation of those appointments and dismissals, based on the merits and capacity of the officials. This article explains that latest evolution and its consequences.

\section{Keywords}

Civil Service; Public appointments; Administrative discretion; Judicial review; Motivation. 


\section{SUMARIO}

I. LA CONSIDERACIÓN TRADICIONAL DE LOS NOMBRAMIENTOS POR LIBRE DESIGNACIÓN COMO POTESTAD DISCRECIONAL BASADA EN LA CONFIANZA Y SUJETA A ESCASOS LÍMITES JURÍDICOS. II. EL SISTEMA DE LIBRE DESIGNACIÓN EN EL ESTATUTO BÁSICO DEL EMPLEADO PÚBLICO. III. SOBRE LOS LÍMITES DE LA POTESTAD DISCRECIONAL DE LIBRE DESIGNACIÓN DEDUCIDOS POR LA RECIENTE JURISPRUDENCIA. IV. SOBRE LOS LÍMITES DE LA FACULTAD DE CESE DE LOS FUNCIONARIOS EN LOS PUESTOS CUBIERTOS POR LIBRE DESIGNACIÓN. V. ALGUNAS CONCLUSIONES, MIRANDO AL FUTURO.

\section{LA CONSIDERACIÓN TRADICIONAL DE LOS NOMBRAMIENTOS POR LIBRE DESIGNACIÓN COMO POTESTAD DISCRECIONAL BASADA EN LA CONFIANZA Y SUJETA A ESCASOS LÍMITES JURÍDICOS}

El procedimiento de provisión de puestos de trabajo en la función pública mediante libre designación ha sido siempre objeto de polémica y de crítica, más o menos aguda, en el ámbito jurídico y entre los propios funcionarios.

En realidad, se trata de un sistema que ha existido siempre en nuestro ordenamiento para acceder a ciertos cargos en las Administraciones públicas que están reservados a funcionarios de carrera, sobre todo los de mayor nivel de responsabilidad. También existe, con unas u otras variantes, en muchos de los Estados democráticos de nuestro entorno. Y es que para el desempeño de puestos que requieren un grado cualificado de confianza personal, como las secretarías de los altos cargos, o la valoración específica de aptitudes como la capacidad de liderazgo o de dirección, o de iniciativa o innovación, o de compromiso con el servicio, resultan poco apropiados métodos de selección más formales o reglados, basados sobre todo en los años de servicio, las titulaciones, actividades formativas e inclusive las meras evaluaciones favorables en otros puestos que no precisan de tales aptitudes. Un margen de discrecionalidad en la apreciación de la idoneidad para la provisión de aquellos puestos puede ser razonablemente necesario y entiendo que en la mayoría de los casos se hace un uso correcto de tal discrecionalidad de 
nombramiento, pues a las autoridades y altos cargos les interesa normalmente contar para puestos de responsabilidad o confianza con los funcionarios adecuados. El problema es que con relativa frecuencia las facultades de libre designación se han utilizado y se utilizan por quienes las detentan de manera improcedente o desviada, para favorecer a personas con las que mantienen una relación subjetiva de fidelidad o afinidad ideológica y a veces de amistad o parentesco, en detrimento de otras más capaces.

Estas prácticas son manifiestamente contrarias a los principios del Estado de derecho, ya sea la igualdad o la prohibición de arbitrariedad, así como al interés público y a los legítimos intereses de muchos funcionarios. Así parece percibirlo cada vez más la opinión pública, como demuestra el repudio social a algunos nombramientos recientes teñidos de nepotismo o amiguismo, que han salido a la luz pública en particular en el ámbito de las Administraciones locales, aunque no solo. Sin embargo, ni la legislación ni la jurisprudencia han puesto coto efectivo a las mismas, pues no han establecido hasta ahora límites claros y terminantes al ejercicio de la discrecionalidad gubernativa que comportan tales nombramientos. Esta situación parece estar empezando a cambiar desde hace algunos ańos, más por obra de los tribunales que de los legisladores, tal como se trata de explicar en estas páginas.

En efecto, superando el modelo burocrático tradicional de carrera de los funcionarios públicos, fundado en el ascenso por antigüedad —que no excluía, por cierto, el nombramiento "por elección" del ministro de determinados jefes de administración ${ }^{1}$ — , la Ley de Funcionarios Civiles del Estado de 1964 (texto articulado aprobado por el Decreto 315/1964, de 7 de febrero) dispuso que los puestos vacantes (correspondientes a los cuerpos generales) se cubrieran por concurso, «salvo los que excepcionalmente se califiquen, a propuesta de la Comisión Superior de Personal, como de libre designación» (art. 56). Aunque este último sistema de provisión se configuró como una excepción, la Ley no establecía los casos o circunstancias a que debía ceñirse. Y la consecuencia inmediata fue, en opinión de Luis Morell Ocaña ${ }^{2}$, que todos los puestos situados en los niveles retributivos más altos serían calificados como de libre designación, incluidos los reservados a funcionarios con «especial preparación técnica», lo que consolidó un «estrato funcionarial basado en estrictas lealtades personales».

La Ley de Medidas para la Reforma de la Función Pública 30/1984, de 2 de agosto, que en otros aspectos modificó de manera sustancial nuestro régimen funcionarial, mantuvo, sin embargo, en este la misma posición, disponiendo frente a la regla general del concurso que pudieran proveerse por libre designa-

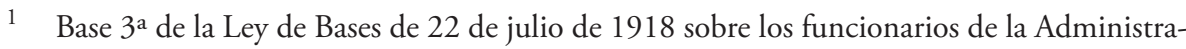
ción Civil del Estado y art. 4 de su Reglamento aprobado por RD de 7 de septiembre de 1918.

2 L. Morell (1994), El sistema de la confianza politica en la Administración Pública, Madrid: Civitas, pág. 94. 
ción "los puestos que se determinen en las relaciones de puestos de trabajo», sin mayores precisiones (art. 20.1.b). Solo tras la doctrina general establecida por la STC 99/1987, de 11 de junio, en el recurso de inconstitucionalidad contra dicha ley, que subrayó las exigencias del principio de mérito en el régimen de la función pública, derivadas de los arts. 23.2 y $103 \mathrm{CE}$, y aunque dicha sentencia no se pronunció sobre el citado art. 20, se consideró oportuno añadir algunos límites y así se hizo por la Ley 23/1988, de 28 de julio. Ratificado el concurso como «sistema normal de provisión», se permitió cubrir por libre designación, en convocatoria pública, aquellos puestos que se determinen en las relaciones de puestos de trabajo «en atención a la naturaleza de sus funciones». Y, en conexión con esta última expresión, un segundo párrafo del art. 20.1.b) estableció que en la Administración del Estado y sus organismos autónomos, incluyendo las entidades gestoras y servicios comunes de la Seguridad Social, solo podían cubrirse por ese sistema los puestos de subdirector general, delegados y directores regionales o provinciales, secretarías de altos cargos, así como aquellos otros «de carácter directivo o de especial responsabilidad» para los que se determine en las relaciones de puestos de trabajo.

La Ley 23/1988 definió al menos, para la Administración estatal, el núcleo característico de los puestos de libre designación, si bien con no poca ambigüedad, implícita en el concepto de puestos de especial responsabilidad. Pero más allá de eso, no introdujo ningún límite sustantivo ni de procedimiento para los nombramientos por este sistema, aparte de exigir la convocatoria pública y, por ende, la apertura a la concurrencia entre los funcionarios interesados, y un informe previo del titular del centro, organismo o unidad a que figure adscrito el puesto convocado [art. 20.1.c)], informe de conformidad cuyo contenido o finalidad ni siquiera se indica. En fin, el art. 20.1.e) añadía que los funcionarios adscritos a un puesto por el procedimiento de libre designación podían ser removidos del mismo «con carácter discrecional».

Esta regulación legal fue desarrollada primero por el Real Decreto 28/1990, de 15 de enero y, después, sin apenas cambios, por el Real Decreto 364/1995, de 10 de marzo, que aprueba el Reglamento general de ingreso del personal al servicio de la Administración General del Estado y de provisión de puestos de trabajo y promoción profesional de los funcionarios civiles de la Administración General del Estado, que está en vigor y es de aplicación supletoria a todos los funcionarios civiles de las distintas Administraciones públicas excluidos de su ámbito de aplicación directa (art. 1.3). El Reglamento solo precisa, sin embargo, algunos contenidos de las convocatorias de provisión por libre designación, como que pueden incluir especificaciones adicionales a las contenidas en la relación de puestos de trabajo y derivadas de la naturaleza de las funciones propias del puesto (art. 52), el plazo para presentar las solicitudes (art. 53) y para resolver (art. 56.1) y la exigencia de determinados informes preceptivos a incluir en el expediente (arts. 54 y 55). Por lo demás, impone motivar las resoluciones de nombramiento solo "por referencia al cumplimiento por parte del candidato 
elegido de los requisitos y especificaciones exigidos en la convocatoria, y la competencia para proceder al mismo", debiendo además quedar acreditada, "como fundamento de la resolución adoptada», la observancia del procedimiento debido (art. 56.2). Este tipo de motivación, de carácter formal, no se extiende a la justificación de las razones de fondo determinantes de la elección de uno entre los candidatos que cumplan los requisitos exigidos. Más aun, en el caso del cese de un funcionario en el puesto de trabajo para el que fue nombrado por libre designación, el Reglamento, reiterando el carácter discrecional de la decisión, señala exclusivamente que la motivación de la misma «se referirá a la competencia para adoptarla» (art. 58.1).

Las primeras leyes de función pública de las comunidades autónomas, aprobadas en las dos últimas décadas del siglo pasado, reprodujeron en líneas generales esta regulación. Eso sí, muchas de ellas se remitían sin más a las relaciones de puestos de trabajo o a los reglamentos de desarrollo para determinar los tipos de puestos a cubrir por libre designación, sin mayor concreción o aludiendo vagamente a la definición de esos puestos «en atención a la naturaleza de sus funciones» ${ }^{3}$; o bien incluyeron un amplio grupo de puestos de trabajo a proveer por ese sistema, como la Ley 6/1985, de ordenación de la Función Pública de Andalucía (art. 26.2), que lo contempla para cubrir nada menos que «el puesto superior jerárquico de cada unidad o dependencia administrativa y los puestos de especial asesoramiento y colaboración personal» ${ }^{4}$. También el art. 101 de la Ley de Bases de Régimen Local de 1985 prevé sin mayores matices la posibilidad de provisión de puestos de funcionarios por libre designación, remitiéndose a las normas que regulen los procedimientos de provisión «en todas las administraciones públicas». Sin olvidar que la Ley 10/1993, de 21 de abril, permitió cubrir por ese procedimiento inclusive los puestos de secretario, interventor y tesorero en las más

3 Entre las primeras, Ley 1/86, de 10 de abril, de la Comunidad de Madrid, art. 51; Ley 2/87, de 30 de marzo, de Canarias, art. 78.3; y el Decreto Foral Legislativo de Navarra 251/1993, de 30 de agosto, art. 34.1; entre las segundas, el Decreto Legislativo 1/1991, de 19 de febrero, de Aragón, art. 30; la Ley 4/1993, de 10 de marzo, de Cantabria, art. 44.1.b); la Ley 3/1990, de 29 de junio, de La Rioja, art. 28.b). En términos similares a la regulación de la Ley estatal de Medidas para la Reforma de la Función Pública, véase la Ley 6/1989, de 6 de julio, del País Vasco, art. 46.3; el Decreto Legislativo 1/1997, de 31 de octubre, de Cataluña, art. 63; el Decreto Legislativo 1/2001, de 26 de enero, de Murcia, art. 51; y la Ley 2/2015, de 29 de abril, de Galicia, art. 92.

4 Más tarde otras leyes incluyeron también listados amplios. Así la Ley 7/2005, de 24 de mayo, de Castilla y León, art. 48.2, que incluye los puestos iguales o similares a jefes de servicio; la Ley 3/2007 de Baleares, de 27 de marzo, art. 79; la Ley 10/2010, de 9 de julio, de la Comunidad Valenciana, art. 102.2, que incluye entre los puestos de libre designación, por cierto, los de conductores de los miembros del Consell y otros altos cargos; la Ley 4/2011, de 10 de marzo, de Castilla-La Mancha, art. 70; o la Ley 13/2015 de Extremadura, de 8 de abril, art. 121; leyes estas últimas posteriores al EBEP de 2007 o tramitadas en paralelo a este. 
importantes entidades locales 5 . En ámbitos sectoriales del empleo público, como, por ejemplo, el art. 29.3 del Estatuto Marco del Personal Estatutario de los Servicios de Salud, se recoge también esa fórmula de provisión, aunque no en todos los casos tiene el mismo grado de aplicación.

Así las cosas, durante mucho tiempo los tribunales intentaron más que nada controlar la expansión inmoderada de los puestos de libre designación. Sobre la base del carácter excepcional de este procedimiento de provisión de puestos, exigieron que, tratándose supuestamente de puestos directivos y de especial responsabilidad, las Administraciones competentes justificaran en cada caso las razones por las que se exceptuaba la provisión por concurso. En virtud de esa doctrina fueron muy numerosos los casos de impugnación de relaciones de puestos de trabajo, especialmente de Administraciones autonómicas y locales, en los que se alegaba la ilegalidad de las determinaciones relativas a la cobertura de puestos por libre designación. Muchos de esos casos llegaron por vía de casación al Tribunal Supremo, que procuró llevar a cabo un control riguroso de los excesos ${ }^{6}$. Hasta que, quizá harta de resolver recursos contra tantas y tantas RPT, la propia Sala de lo Contencioso-Administrativo del Alto Tribunal, Sección 7a, declaró, por STS de 5 de febrero de 2014 (rec. 2986/2012), que las relaciones de puestos de trabajo no son equiparables a los reglamentos o disposiciones de carácter general a efectos procesales, como se entendía hasta entonces, sino una suerte de actos administrativos, que la sentencia denomina actos-condición, pues singularizan para cada puesto las regulaciones generales; de manera que, por ser cuestión de personal y no impugnación de disposiciones generales, los recursos contra las RPT dejaron de tener acceso a la casación, conforme a la regulación de este tipo de recurso entonces vigente.

Con independencia de ello y por lo que ahora más nos interesa, los legisladores, con alguna notoria excepción ${ }^{7}, y$ - lo que es más importante - los

5 Así en las diputaciones provinciales, cabildos y consejos insulares y municipios capitales de provincia y los de más de 100.000 habitantes. Esta ley fue impugnada, entre otras cosas, por considerarse incompatible el sistema de libre designación y libre cese de estos funcionarios con las garantías de imparcialidad y objetividad necesarias en el ejercicio de sus funciones, que son ciertamente funciones de control interno de las corporaciones locales, es decir, de quienes tienen la potestad de nombrarles y cesarles. Pese a lo razonable de esta objeción, la STC 235/2000, de 5 de octubre, desestimó el recurso de inconstitucionalidad.

6 Las sentencias del Tribunal Supremo —y de los Tribunales Superiores de Justicia — sobre la cuestión son numerosísimas y se refieren en buena parte a puestos de jefatura de servicio o equivalentes en las diferentes Administraciones públicas, aunque también a otros. Una exposición sistematizada de esta jurisprudencia (hasta el año 2012) puede verse en J. Cantero Martínez, J. A. Fuentetaja Pastor, L. Maeso Seco y B. Marina Jalvo (M. Sánchez Morón, coord.) (2013), Régimen jurídico de la función pública. Valladolid: Lex Nova, págs. 439-457.

7 Art. 30 del Decreto Legislativo 1/1991, de 19 de febrero, por el que se aprueba el texto refundido de la Ley de Ordenación de la Función Pública de la Comunidad de Aragón, 
diferentes gobiernos y administraciones de todos los niveles entendieron que el procedimiento de libre designación facultaba al órgano competente para nombrar para un puesto de trabajo a quien mejor le pareciera, de entre los funcionarios candidatos, sin más que publicar la correspondiente convocatoria, recabar si acaso algunos informes internos de conformidad con el procedimiento y dictar una resolución confirmando simplemente el cumplimiento de las normas de competencia y del procedimiento debido. Y esta misma interpretación favorable al reconocimiento de un amplísimo margen de discrecionalidad en los nombramientos, con muy escasos matices, fue avalada por la jurisprudencia en su momento.

Baste como muestra de la doctrina general aplicada en la mayoría de los casos la que figura en las SSTS de 10 de enero de 1997 (rec. 554/1995) y 11 de enero de 1997 (rec. 424/1995):

[...] el nombramiento (o la facultad de no nombrar a la persona propuesta) para cargos de libre designación constituye un acto administrativo singular y específico dentro de la categoría general de los actos discrecionales (letra f. del art. 54.1 de la LRJ-PAC), consistiendo la singularidad en que tales nombramientos (o la denegación del nombramiento) se basan en la existencia (o inexistencia) de un motivo de confianza, que la autoridad facultada para la designación ha de tener (o no tener) en la persona designada (o cuya propuesta de designación se rechaza), relación de confianza que sólo puede apreciar esa misma autoridad que verifica el nombramiento. La ley, cuando delimita los cargos de libre designación, está haciendo posible que la Administración ejercite su potestad organizatoria, nombrando para los puestos de dicha clase a la persona en quien la autoridad competente estima que concurren las condiciones necesarias para el desarrollo de los fines públicos que persigue, y que le ofrece una especial confianza para ello, circunstancias que lógicamente variarán según el momento en que se produzca el nombramiento y las personas que ejerzan la autoridad llamada a verificar tal nombramiento, que, en un sistema democrático, pueden pretender en momentos distintos de tiempo finalidades diferentes en razón de su ideología. De lo expuesto se deriva que, respetándose los elementos reglados en el nombramiento, la autoridad a que la ley confiere la facultad de libre designación para un cargo determinado pueda otorgar a una u otra persona su confianza para el desempeño del cargo, sin estar sometida al requisito formal de hacer una exposición de los motivos en virtud de los cuales prefiere a determinada persona respecto a otra u otras o bien no concede esa confianza a determinada persona. A ello se añade la consideración de que la referencia a las condiciones subjetivas determinantes de la confianza que concurren en el designado o no designado para un cargo no serían susceptibles de fiscalización en vía jurisdiccional, que es el fundamento esencial del requisito de la motivación de los actos administrativos. La motivación de la resolución de no designar para un cargo de libre nombramiento a la persona propuesta (supuesto del presente litigio), que tendría que limitarse a una referencia

según el cual, la provisión de puestos clasificados como de libre designación «se realizará atendiendo a criterios de mérito y capacidad» y a propuesta "razonada» del consejero titular del Departamento, mientras que los funcionarios así designados podrán ser removidos de su puesto discrecionalmente, pero «mediante resolución motivada». 
a que las condiciones concurrentes en la persona rechazada no se estimaban suficientes por la autoridad competente para depositar en ella su confianza para el desempeño del cargo, según sus criterios sobre la dirección de la cosa pública, no se traduciría en una proposición con eficacia jurídica, no dejando de ser sino la simple expresión de la facultad discrecional que es el verdadero fundamento o motivación del acto administrativo.

Esta doctrina se reitera, en términos similares, en muchas otras sentencias ${ }^{8}$, aunque también las hay que se refieren al menos a la desviación de poder como límite intrínseco de la facultad de libre designación, sobre la base de que dicha facultad no obsta a la aplicación de los principios de mérito y capacidad en el ascenso de los funcionarios. Así, por ejemplo, las SSTS de 16 de mayo de 1989 (rec. 345/1986) y 4 de noviembre de 1993 (rec. 4274/1991). Y esta última es la tesis que acoge también el Tribunal Constitucional en la STC 235/2000, de 5 de octubre, relativa a la libre designación de secretarios, interventores y tesoreros en municipios de mayor población y otras entidades locales:

[...] la facultad de libre designación no atribuye al órgano de decisión una especie de poder omnímodo a fin de decidir como tenga por conveniente, con olvido de que el servicio del interés público es la esencia y el fundamento del ejercicio de toda potestad administrativa, con la consecuencia, en todo caso, de la eventual apreciación, con ocasión del oportuno control judicial ex art. 106.1 CE, del vicio de desviación de poder de constatarse una marginación indebida de los principios de mérito y capacidad?

Ahora bien, la desviación de poder debe probarse de manera concluyente por quien la alega, lo que no suele ser fácil ${ }^{10}$. Y, en cualquier caso, esa doctrina arroja exclusivamente sobre los interesados la carga de probar que la Administración actuó contra los citados principios constitucionales y el interés público, ya que no impone ninguna garantía de procedimiento ni exige a priori una motivación sustantiva de los nombramientos.

8 Véase al respecto J. Cantero Martínez, J. A. Fuentetaja Pastor, L. Maeso Seco y B. Marina Jalvo (M. Sánchez Morón, coord.), Régimen jurídico de la función pública, cit., págs. 458 ss.

9 La STC 235/2000 se apoya a su vez en la doctrina que fija el límite a las facultades de libre designación en el principio de interdicción de la arbitrariedad, establecida ya en SSTC 18/1987, de 16 de febrero, 207/1988, de 8 de noviembre, y 10/1989, de 24 de enero. En sentido similar y recalcando la exigencia constitucional de publicidad de las convocatorias de libre designación, véase la STC 221/2004, de 29 de noviembre. También la STC 129/2007, de 4 de junio, que considera contrario al principio de igualdad la exclusión injustificada de ciertos grupos de funcionarios para concurrir a una convocatoria.

10 Véase, sin embargo, un supuesto reciente de desviación de poder en procedimiento de libre designación de un cargo en el Defensor del Pueblo, en STS de 8 de octubre de 2019 (rec. 473/2017). 
Por lo demás, la jurisprudencia mayoritaria del período aceptaba también la práctica libertad de cese de los funcionarios de los puestos a los que accedían por libre designación, ya que implicaba una pérdida de confianza en el designado, razón suficiente para la destitución de quien había accedido al puesto en virtud precisamente de la confianza en él depositada, que no requería de mayor justificación ${ }^{11}$.

\section{EL SISTEMA DE LIBRE DESIGNACIÓN EN EL ESTATUTO BÁSICO DEL EMPLEADO PÚBLICO}

Los defectos y la insatisfacción ante el sistema de provisión de puestos de trabajo en la función pública regulados por las mencionadas leyes se pusieron de manifiesto por el Informe de la Comisión para el Estudio y Preparación del Estatuto Básico del Empleado Público ${ }^{12}$. Junto a la excesiva rigidez y formalismo de los procedimientos de concurso, el Informe criticaba también la «discrecionalidad prácticamente absoluta» que regía en los procedimientos de libre designación, ya que no era necesario en tales casos «definir, acreditar ni motivar la concurrencia de méritos de los interesados».

La Comisión proponía al respecto una revisión a fondo del sistema, en el que sí podrían preverse "para puestos determinados y reducidos», procedimientos de elección en los que el órgano competente goce de un cierto margen de discrecionalidad, se llamaran o no libre designación. Distinguía al efecto entre aquellos puestos cuyo desempeño requiere condiciones de estricta confianza personal (como, por ejemplo, las secretarías de altos cargos) y otros en los que la selección debe basarse en requisitos previamente conocidos y en una acreditación de la idoneidad de los candidatos, para lo que no se debe prescindir de la intervención de órganos o comisiones de valoración, sea para avalar la capacidad de los candidatos o para preseleccionar o proponer a varios de ellos al órgano competente para nombrarlos. Igualmente, la Comisión entendía que el nombramiento discrecional no tiene por qué implicar libre cese, salvo si se trata de los titulares de aquellos puestos que requieran un estricta confianza personal, y que debería garantizarse a los designados un plazo mínimo para el desempeño del cargo, a menos que concurran causas objetivas de remoción, aplicables por resolución motivada.

Sin embargo, el texto legal del Estatuto Básico del Empleado Público (EBEP) aprobado por las Cortes (Ley 7/2007, de 12 de abril) recogió solo en parte estas sugerencias y mantuvo una regulación más apegada al modelo tradicional. Con

11 Véase J. Cantero Martínez, J. A. Fuentetaja Pastor, L. Maeso Seco y B. Marina Jalvo (M. Sánchez Morón, coord.), Régimen jurídico de la función pública, cit., págs. 467 ss.

12 Informe publicado por el Instituto Nacional de Administración Pública en abril de 2005, págs. 107 ss. 
todo, introdujo al menos novedades conceptuales relevantes, que han dado pie a una evolución de la jurisprudencia impensable años atrás.

El art. 80.2 EBEP (hoy TREBEP) permite a las leyes de función pública que se dicten en su desarrollo determinar los puestos que puedan cubrirse por libre designación, en razón de «su especial responsabilidad y confianza», como venía sucediendo. Por cierto que las escasas leyes de desarrollo del EBEP aprobadas hasta ahora han determinado esos supuestos con bastante amplitud ${ }^{13}$. Pero en el apdo. 1 de ese mismo art. 80 se define la libre designación, que exige siempre convocatoria pública, como «la apreciación discrecional por el órgano competente de la idoneidad de los candidatos en relación con los requisitos exigidos para el desempeńo del puesto». La definición legal es importante, ya que significa que la discrecionalidad de que goza quien tiene la facultad de nombramiento no es de naturaleza política o volitiva, basada en la confianza personal, sino relativa solo a la apreciación de los méritos y capacidad de los candidatos. Son exclusivamente esos criterios los que deben guiar la elección, aunque no deba atenerse a un baremo preestablecido o a pautas estrictamente regladas. Por eso el art. 80.3 prevé que el órgano competente para el nombramiento podrá recabar la intervención de especialistas, «que permitan apreciar la idoneidad de los candidatos».

Ciertamente, acudir a la intervención de especialistas o de alguna comisión de valoración en estos casos sigue siendo muy poco habitual en la práctica. Y eso no es sino una muestra de que en la mayoría de los casos las autoridades titulares de los órganos competentes para estos nombramientos no han asimilado aún los cambios que comporta el EBEP en el sistema de libre designación. Pues no es su preferencia subjetiva o la relación de confianza personal lo que debe contar, sino la apreciación, por discrecional que sea, de méritos y capacidades, algo que ya dejó claro el Tribunal Constitucional en su STC 235/2000, citada, y que permite profundizar en el control judicial de esas decisiones, tal como ha empezado a ocurrir.

En efecto, argumenta la STC 235/2000 en el FJ13, refiriéndose a los procedimientos de concurso y libre designación, que:

[...] la finalidad a que ambos sirven es la misma: la atribución, de acuerdo con la lógica de cada procedimiento, de determinados puestos de trabajo a aquellos funcionarios en quienes concurran, desde la óptica de los principios de mérito y capacidad, la cualificación e idoneidad precisas para el mejor y más correcto desempeño de las funciones anudadas a cada puesto. Que la adjudicación sea en el caso del concurso la consecuencia de la baremación, más o menos automática, de los méritos aportados, según lo dispuesto en la oportuna convocatoria, en tanto que en el sistema de libre designación se produzca como resultado de la apreciación (dotada, como es obvio, de una evidente connotación de discrecionalidad o, si se prefiere, de un cierto margen de libertad) que el órgano decisor se haya forjado a la vista del historial profesional de los candidatos o aspirantes, es indiferente desde la perspectiva

13 Tal como ya se ha expuesto supra en la nota 4. 
del genérico estatuto funcionarial de la persona que finalmente resulte adjudicataria del puesto en cuestión. No nos hallamos aquí en presencia de nombramientos para cargos políticos, caracterizados por la libérrima decisión de quien sea competente para efectuar el nombramiento; ni ante la designación de personal eventual, cualificado, según el art. 20.2, párrafo segundo, de la Ley 30/1984, por la «confianza o asesoramiento especial» de las funciones que pueden encomendársele. La confianza que, en este sentido, puede predicarse de la libre designación, en cuanto modo de provisión entre funcionarios de puestos de trabajo, es la que se deriva de la aptitud profesional del candidato, puesta de manifiesto en los méritos esgrimidos, esto es, en su historial funcionarial.

Algo similar debería predicarse del cese de los titulares de los puestos de trabajo provistos por libre designación. Pues, aunque el art. 80.4 del EBEP dispuso que "podrán ser cesados discrecionalmente», tampoco cabe configurar dicha discrecionalidad como potestad derivada de una relación de confianza personal o subjetiva. Siendo la apreciación discrecional de la idoneidad del nombrado, sobre la base de sus méritos y capacidad, lo que cuenta para designarle, debe ser lógicamente una nueva apreciación de falta de idoneidad lo que puede justificar su destitución. Y así se está empezando también a considerar por la jurisprudencia de los tribunales.

\section{SOBRE LOS LÍMITES DE LA POTESTAD DISCRECIONAL DE LIBRE DESIGNACIÓN DEDUCIDOS POR LA RECIENTE JURISPRUDENCIA}

El Tribunal Supremo empezó, por su parte, a cambiar su doctrina sobre la libre designación, en relación con los nombramientos discrecionales para determinados puestos en el Poder Judicial, que prevé el art. 333 de la Ley Orgánica del Poder Judicial. Fue en la STS de 29 de mayo de 2006 (rec. 309/2004), que resolvió el recurso contra la decisión del Consejo General del Poder Judicial de nombrar al presidente de la Sala de lo Penal de la Audiencia Nacional. Según dicha sentencia, no se está en este caso ante un nombramiento por libre designación «en su acepción tradicional», basada en la confianza personal y la libertad de cese, sino ante una potestad de tipo mixto, pues el Consejo General del Poder Judicial debe tener en cuenta necesariamente el currículum de los candidatos, aunque no puede negarse que goza al efecto de «un amplio margen de libertad de apreciación». Para el Tribunal Supremo, sin embargo, ese margen "no puede implicar en modo alguno que la decisión sobre la cobertura de la plaza vacante devenga fruto de un voluntarismo inmotivado y carente de cualquier posibilidad de control». Y ello porque la confianza que se deposita en el nombramiento «no puede entenderse basada en apreciaciones de oportunidad política, afinidad personal o adscripción ideológica, sino en razones exclusivas de aptitud profesional para el desempeńo del puesto concernido». A partir de esta tesis, en la que resuena el eco de los argumentos de la STC 235/2000, se considera que el control judicial puede 
extenderse sobre el cumplimiento del procedimiento debido y asimismo sobre la motivación de la decisión, que ha de ser suficiente. La sentencia, en consecuencia, declara que ha de «superar» la doctrina establecida por otras de la misma sala, de 3 de febrero de 1997 y 30 de noviembre de 1999, que admitían la imposibilidad de controlar el núcleo de la decisión discrecional del Consejo General del Poder Judicial en este tipo de casos y, no sin un extenso voto particular, anula el acto impugnado por defectos de procedimiento y, sobre todo, de motivación. Hay, pues, aquí un declarado overrule, un cambio consciente y radical de la doctrina previa del propio Tribunal Supremo.

Lo importante es que esta nueva doctrina, ratificada por alguna otra sentencia relativa a nombramientos para órganos judiciales (STS de 27 de noviembre de 2007 , rec. $407 / 2006$ ) y a la que viene aludirse de pasada en otros casos (SSTS de 4 y 18 de mayo de 2009, recs. 5235 y 6529/2005, sobre nombramientos en el cuerpo de los Mossos d'Esquadra), se aplicó poco después directamente al sistema de libre designación previsto en la legislación general de función pública, por la trascendental STS de 30 de septiembre de 2009 (rec. 28/2006), que resuelve un recurso ordinario contra el nombramiento de un cargo en el Tribunal de Cuentas. La fundamentación de esta sentencia, reveladora de un claro activismo judicial, aunque coherente con la evolución del concepto de libre designación que recogen la jurisprudencia constitucional y el Estatuto Básico del Empleado Público, es concluyente:

La decisión de las cuestiones que son suscitadas en el actual litigio [...] aconseja comenzar con unas consideraciones sobre la significación que tiene el procedimiento de libre designación legalmente establecido para la provisión de puestos de trabajo.

Para ello es trasladable a estos nombramientos funcionariales por libre designación la doctrina que el Pleno de esta Sala Tercera del Tribunal Supremo ha sentado sobre los nombramientos discrecionales para cargos jurisdiccionales en las Sentencias de 29 de mayo de 2006 (recurso 309/2004) y 27 de noviembre de 2007 (recurso 407/2006), en las que expresamente se declaran superados los anteriores pronunciamientos jurisprudenciales (se citan los contenidos en las SSTS de 3 de febrero de 1997 y 30 de noviembre de 1999) que habían apuntado la innecesariedad e inexigibilidad de motivación en esa clase de nombramientos. El núcleo de esa nueva jurisprudencia se apoya en la idea principal de que la libertad legalmente reconocida para estos nombramientos discrecionales no es absoluta sino que tiene unos límites. Límites que están representados por las exigencias que resultan inexcusables para demostrar que la potestad de nombramiento respetó estos mandatos constitucionales: que el acto de nombramiento no fue mero voluntarismo y cumplió debidamente con el imperativo constitucional de interdicción de la arbitrariedad (art. 9.3 $\mathrm{CE}$ ); que respetó, en relación a todos los aspirantes, el derecho fundamental de todos ellos a acceder en condiciones de igualdad a las funciones y cargos públicos (art. 23.2 CE); y que el criterio material que finalmente decidió el nombramiento se ajustó a las pautas que encarnan los principios de mérito y capacidad (103.3 CE). A partir de esa idea se declara también que las exigencias en que se traducen esos lí- 
mites mínimos son de carácter sustantivo y formal. La exigencia sustantiva consiste en la obligación, a la vista de la singularidad de la plaza, de identificar claramente la clase de méritos que han sido considerados prioritarios para decidir la preferencia determinante del nombramiento. Y la exigencia formal está referida, entre otras cosas, a la necesidad de precisar las concretas circunstancias consideradas en la persona nombrada para individualizar en ella el superior nivel de mérito y capacidad que le haga más acreedora para el nombramiento.

[...] Las consecuencias que se derivan de lo anterior para los nombramientos realizados por el procedimiento de libre designación regulado en el art. 20.1.b) de la Ley 30/1984, de 2 de agosto, de Medidas para la Reforma de la Función pública [...] son las siguientes:

a) En el procedimiento de libre designación rigen también los principios de mérito y capacidad, pero, a diferencia del concurso, en que están tasados o predeterminados los que ha decidir el nombramiento, la Administración tiene reconocida una amplia libertad para decidir, a la vista de las singulares circunstancias existentes en el puesto de cuya provisión se trate, cuáles son los hechos y condiciones que, desde la perspectiva de los intereses generales, resultan más idóneos o convenientes para el mejor desempeño del puesto.

b) La motivación de estos nombramientos, que es obligada en virtud de lo establecido en el art. 54.2 de la Ley 30/1992, de 26 de noviembre, de Régimen Jurídico de las Administraciones Públicas y del Procedimiento Común, no podrá quedar limitada a lo que literalmente establece el art. 56.2 del Reglamento General de Ingreso del personal al servicio de la Administración General del Estado y de Provisión de Puestos de Trabajo y Promoción Profesional de los Funcionarios Civiles de la Administración General del Estado, aprobado por Real Decreto 364/1995, de 10 de marzo (que sólo la refiere al cumplimiento por el candidato elegido de los requisitos y las especificaciones exigidos en la convocatoria y la competencia para proceder al nombramiento). Lo establecido en este precepto reglamentario sobre la motivación deberá ser completado con esas exigencias que, según esa nueva jurisprudencia que ha sido expuesta, resultan inexcusables para justificar el debido cumplimiento de los mandatos contenidos en los arts. 9.3, 23 y 103.3 CE, y esto significa que la motivación deberá incluir también estos dos extremos: los concretos criterios de interés general elegidos como prioritarios para decidir el nombramiento; y cuáles son las cualidades o condiciones personales y profesionales que han sido consideradas en el funcionario nombrado para apreciar que aquellos criterios concurren en él en mayor medida que en el resto de los solicitantes.

c) El Informe que ha de ser emitido por el titular del centro, organismo o unidad a que esté adscrito el puesto [arts. 20.1.c) de la Ley 30/1984 y 54.1 del Reglamento General de Provisión antes mencionado] es un elemento muy importante en el procedimiento de libre designación, pues está dirigido a ofrecer la información sobre las características del puesto que resulta necesaria para definir los criterios que deben decidir el nombramiento. Esta importancia hace que se proyecten sobre este trámite de manera muy especial las garantías que son demandadas por los principios de objetividad y de igualdad (arts. 103.3 y 23.2 CE) y, consiguientemente, determi- 
nan la aplicación a quien ha de emitirlo de las causas de abstención establecidas en el art. 28 de la Ley 30/1992.

Esta nueva doctrina ha sido refrendada luego por SSTS de 19 de octubre de 2009 (rec. 58/2007), 23 de noviembre de 2009 (rec. 372/2008), 5 de febrero de 2010 (rec. 72/2005), 3 de diciembre de 2012 (rec. 339/2012) y 11 de noviembre de 2014 (rec. 149/2013), entre otras, y recogida en numerosas sentencias de Juzgados de lo Contencioso-Administrativo y Tribunales Superiores de Justicia ${ }^{14}$. Además, en una última y reciente STS de 30 de abril de 2019 (rec. 117/2017), el Tribunal Supremo viene a formular algunas consideraciones complementarias sobre el tipo de discrecionalidad que se ejerce en estos casos y sobre la motivación debida de los nombramientos. Matices importantes, porque en el caso que enjuicia - una nueva provisión por libre designación en el Tribunal de Cuentas - la resolución había sido motivada en cuanto al fondo, es decir, en relación con las aptitudes de cada candidato:

Ninguna duda hay de que la adjudicación del puesto controvertido se ha fundamentado en una extensa motivación, la que ofrece el informe-propuesta del Consejero de Cuentas del Departamento Tercero de la Sección de Enjuiciamiento que, como nos dice el Abogado del Estado, tiene en consideración los méritos de los distintos solicitantes y destaca los aspectos sobresalientes que advierte en aquél al que propone que se le adjudique. De igual modo, también está claro que cabe la motivación in aliunde, por lo que la remisión a o la aceptación de este informe-propuesta podría satisfacer la exigencia de justificar una decisión para la que el Tribunal de Cuentas dispone de un amplio margen de discrecionalidad técnica, de no ser por cuanto vamos a explicar.

Dicho lo cual, la Sala examina detenidamente esa motivación, para concluir que es inconsistente en lo que atañe al reconocimiento de los méritos del candidato elegido, por lo que estima el recurso y anula el nombramiento. Y sobre esta base termina declarando lo siguiente:

Tal como resulta de la jurisprudencia invocada por las partes, esta forma de provisión de puestos de trabajo confiere a la Administración un amplio margen de decisión en el que, desde luego, juega la discrecionalidad técnica, la cual debe

14 Por ejemplo, en STSJ de Madrid de 7 de febrero de 2017 (rec. 981/2014), STSJ de Andalucía-Málaga, de 27 de marzo de 2019 (rec. 218/2018), STSJ de Castilla-La Mancha de 2 de mayo de 2019 (rec. 354/2017), por referirnos solo a algunas recientes. También adopta la misma doctrina la STSJ de Aragón de 9 de noviembre de 2018 (rec. 179/2018), aunque aplicándola a un nombramiento en comisión de servicios. Pero también pueden seguir encontrándose algunos fallos que mantienen la doctrina «antigua», sobre el carácter puramente discrecional de los nombramientos por libre designación sobre la base de la confianza personal, y así, por ejemplo, la STSJ de Andalucía-Granada, de 19 de febrero de 2019 (rec. 85/2015). 
ser respetada al someterla al control jurisdiccional. No obstante, esa misma jurisprudencia no deja de poner de relieve que el ejercicio de toda discrecionalidad administrativa es compatible con la fiscalización judicial del respeto a los elementos reglados que la circundan y con el examen de los que se han llamado aledaños de la decisión final. Y destaca, asimismo, que esa discrecionalidad ha de respetar siempre el límite que el art. 9.3 de la Constitución impone a los poderes públicos: el de la interdicción de la arbitrariedad. De igual modo, señala que, a fin de que sea posible determinar el correcto ejercicio de las potestades discrecionales, ha de ir acompañado en supuestos como este de una motivación suficiente en términos de mérito y capacidad y de lo requerido en la convocatoria para excluirla.

Es decir, la discrecionalidad que se ejerce en el caso de los nombramientos de funcionarios para puestos de libre designación tiene naturaleza de discrecionalidad técnica, pues solo puede basarse en la apreciación técnica y objetiva de los méritos de los candidatos, sin margen alguno para expresar ningún tipo de preferencia personal.

Esta caracterización da pie a un control judicial más intenso o incisivo de las resoluciones administrativas de los procedimientos de libre designación. Pues no basta ya con motivar esos nombramientos de cualquier manera, sino que será necesario dar cuenta de las razones reales de la decisión, de forma congruente y adecuada. En cierto modo, se traslada a estas decisiones el estándar de control judicial ya establecido por el Tribunal Supremo en los casos de enjuiciamiento de las resoluciones de procesos selectivos para el ingreso en la función pública, que se ha venido depurando y precisando también desde hace algunos años ${ }^{15}$.

Esto no supone que pueda sustituirse sin más la valoración de los méritos de los candidatos efectuada por el órgano administrativo competente por la que pueda realizar un órgano judicial en virtud de las alegaciones y pruebas del proceso, tal como declaran, por ejemplo, en materia de acceso a la función pública, las SSTS de 16 y 23 de septiembre de 2014 (recs. 3157/2013 y 3462/2013 respectivamente) ${ }^{16}$ y de 14 de marzo de 2018 (rec. 2762/2015). Pero sí que implica una revisión de la motivación del acto discrecional para constatar que la Administración no ha incurrido en un error técnico o en cualquier tipo de desviación, sino que incorpora una justificación razonable ${ }^{17}$.

15 Sobre ello, M. Sánchez Morón (2019), Derecho de la Función Pública, 12a ed., págs. 161 ss.

Un comentario de las mismas en M. Sánchez Morón (2015), «Sobre la discrecionalidad técnica y la sana crítica», Revista de Administración Pública, 197, págs. 209 ss.

17 No es ocioso, en relación con ello, hacer referencia a otra sentencia contemporánea de la misma sala y sección, STS de 4 de abril de 2019 (rec. 634/2017), en la que se desestima el recurso contra un cese de un cargo de libre designación en el propio Tribunal de Cuentas. Se trataba, sin embargo, de un recurso interpuesto por el procedimiento especial en materia de derechos fundamentales, pues el recurrente alegaba como violado el derecho a su indemnidad como representante sindical. En este caso, el Tribunal de Cuentas no solo había dispuesto el cese, sino que también había abierto expediente disciplinario contra el 


\section{SOBRE LOS LÍMITES DE LA FACULTAD DE CESE DE LOS FUNCIONARIOS EN LOS PUESTOS CUBIERTOS POR LIBRE DESIGNACIÓN}

Toda esa interesante evolución jurisprudencial ha venido a cerrarse, por el momento, con otra importante sentencia de la Sala $3^{\text {a }}$ del Tribunal Supremo, la STS de 19 de septiembre de 2019 (rec. 2740/2017) ${ }^{18}$. Se trata en este caso de la resolución de un recurso de casación por la que el Tribunal pretende fijar la doctrina sobre la cuestión, de conformidad con la nueva regulación de este recurso.

Hasta ahora la doctrina mayoritaria sobre el cese en ese tipo de puestos venía a confirmar la naturaleza discrecional de la decisión, en tanto que fundada en la pérdida de la confianza depositada en el nombramiento. Una doctrina esta congruente con el mencionado art. 58.1 del Reglamento general de ingreso, provisión de puestos de trabajo y promoción profesional de los funcionarios de 1995. Esa doctrina se expone con toda claridad, por ejemplo, en STS de 13 de junio de 1997 (rec. 697/1994), según la cual la resolución de cese no precisa exteriorizar las razones en que se basa, ya que lo que cuenta es dicha pérdida de confianza, que debe considerarse implícita ${ }^{19}$. Y se reitera en muchas otras sentencias de la Audiencia Nacional y los Tribunales Superiores de Justicia ${ }^{20}$. Aunque también hay alguna jurisprudencia menor minoritaria, que ha venido exigiendo una motivación adecuada del cese, no limitada a la competencia para acordarlo ${ }^{21}$.

Por su parte, el Tribunal Constitucional había opuesto que el cese discrecional de un funcionario o funcionaria en un puesto de libre designación no puede suponer vulneración de los derechos fundamentales. Y en aquellos casos en que

interesado por supuestas irregularidades en la tramitación de algunos procedimientos. El Tribunal Supremo, a la vista de las circunstancias, rechaza que se haya infringido la libertad sindical del recurrente. Aunque es el único motivo del recurso, habida cuenta del tipo de procedimiento contencioso elegido, es obvio que el Tribunal Supremo no considera en este caso el cese carente de fundamento, habida cuenta también de que se declara que la causa de los actos recurridos es exclusivamente la responsabilidad profesional del cesado.

18 La sentencia ha sido ya objeto de recensión y de un breve comentario por T. Font i Llovet, A. Peñalver Cabré, F. Rodríguez Pontón y J. Tornos Mas, en el marco de las «Notas de jurisprudencia contencioso-administrativa» incluidas en el número 210 de esta revista, págs. 324-331.

19 Es sintomático que, en el caso que resuelve esta sentencia, el motivo del cese guarda relación con las críticas expresadas por el cesado hacia un superior, supuesto similar al que subyace a la STS de 19 de septiembre de 2019, que cambia la jurisprudencia.

20 Entre las más recientes, puede verse, por ejemplo, las SSSTJ de Andalucía-Granada de 6 de julio de 2018 (rec. 668/2018) y 19 de febrero de 2019 (rec. 82/2015) y la STSJ de Madrid de 10 de noviembre de 2017 (rec. 157/2016).

21 Por ejemplo, STSJ de Castilla-La Mancha de 20 de junio de 2014 (rec. 174/2013), STSJ de Andalucía-Sevilla de 14 de julio de 2017 (rec. 779/2015), y STSJ de Baleares de 5 de septiembre de 2017 (rec. 146/2017). 
existan indicios de que pueda ocurrir así, por ser el motivo real la disconformidad de la Administración con las actividades sindicales del cesado o la discriminación indirecta que puede derivarse del anuncio de un embarazo, o la infracción del derecho a la ejecución de resoluciones judiciales, la Administración tiene la carga de motivar y probar que obedece efectivamente a motivos distintos, razonables y justificados (SSTC 17/1996, de 7 de febrero, 114/2002, de 20 de mayo, 98/2003, de 2 de junio, 79/2004, de 5 de mayo, 216/2005, de 12 de septiembre, 92/2009, de 20 de abril, entre otras). Pero la jurisprudencia constitucional no se había adentrado, en cambio, en la cuestión de la validez del libre cese, en cuanto tal, de un puesto ocupado por libre designación, quizá por considerarla una cuestión de mera legalidad ordinaria.

El hecho que da lugar a la referida STS de 19 de septiembre de 2019 es el cese de un funcionario como jefe de área en el Consejo de Seguridad Nuclear, cargo al que accedió en su momento por libre designación, cese que fue confirmado en la instancia por sentencia de la Audiencia Nacional. La peculiaridad del caso es que el cese se produjo a raíz de una crítica realizada por el funcionario sobre la revisión de un procedimiento técnico utilizado por el Consejo de Seguridad Nuclear, acusando a su superior jerárquico de aprobar ese cambio «por la puerta de atrás", de modo que se favorecía a los operadores de centrales nucleares. La sentencia de la Audiencia Nacional recurrida en casación ${ }^{22}$ había partido de la jurisprudencia tradicional, según la cual basta la pérdida de confianza para entender justificado el cese, sin que sea necesario exponer las razones de esa pérdida. En el caso concreto, además, parece claro que fueron las críticas o acusaciones a un superior, de las que el cesado no se retractó, las que explican la pérdida de confianza, sin entrar en el correspondiente juicio de valor. Pero el Tribunal Supremo estimó en su Auto de admisión de 25 de octubre de 2017 que es cuestión de interés casacional «determinar cuál es el contenido del deber de motivación exigible en las resoluciones administrativas que acuerdan el cese de funcionarios públicos en puestos de libre designación, y si, a tal efecto, resulta extensible al cese en dichos puestos la doctrina jurisprudencial establecida en relación con su provisión».

A tal efecto recuerda la sentencia que los cargos de libre designación no son como los cargos de personal eventual, que se nombran en virtud de razones de estricta confianza de la autoridad competente, que puede cesar al nombrado «sin dar especial razón", sino que son puestos que son provistos por un procedimiento en el que hay un componente de confianza, pero basado en las cualidades profesionales del designado. En consecuencia, la provisión de estas plazas está sometida a los principios de igualdad, mérito, capacidad y publicidad, según la legislación vigente; y aunque la idoneidad del funcionario nombrado, que integra la confianza en el correcto desempeño del puesto, es apreciada por el órgano competente, la designación está sujeta al deber de motivar, en los términos de la jurisprudencia que ya hemos expuesto aquí. De todo ello, interpretando la legislación en vigor

22 SAN de 23 de marzo de 2017 (rec. 488/2015). 
[art. 80.4 del Texto Refundido del EBEP, art. 58.1 del Reglamento de provisión de puestos de trabajo de 1995 y art. 35.1.i) de la vigente Ley 39/2015, del Procedimiento Administrativo Común, relativo a la motivación de los actos], se concluye en relación con el cese en los puestos de libre designación la siguiente doctrina:

$\left.1^{\circ}\right)$ El funcionario de carrera que desempeńa un puesto clasificado como de libre designación tiene un mero interés en su permanencia, no un derecho a la inamovilidad en ese concreto puesto, algo propio de los provistos mediante concurso reglado. Ese mero interés trae su causa en que la designación para el puesto se basa en un juicio de libre apreciación, por lo que quien lo designó puede juzgar que las condiciones subjetivas u objetivas, tenidas en cuenta para la designación, pueden haber desaparecido o cambiado, teniendo en cuenta el interés general que se satisface desde el desempeño del puesto.

$2^{\circ}$ ) Como el acto de nombramiento, también el de cese debe ajustarse a exigencias formales obvias como, por ejemplo, que lo acuerde el órgano competente o la adecuada formación —en su caso- de la voluntad si es un órgano colegiado y a tales exigencias formales cabe añadir la motivación, si bien con la debida modulación.

30) Esta motivación ciertamente debe ir más allá de lo previsto en el art. 58.1, párrafo segundo, del RGPPT, según el cual «la motivación de esta resolución se referirá a la competencia para adoptarla». Por tanto, al funcionario cesado debe dársele razón de por qué las razones de oportunidad, basadas en la confianza e idoneidad apreciada para el puesto y que llevaron a su elección, ya no concurren o si concurren qué otra circunstancia objetiva determina la pertinencia del cese.

4º) La razón o razones del cese no serán enjuiciables en lo que tiene de libre apreciación; ahora bien, es exigible que se explicite evitándose expresiones opacas, estandarizadas, que puedan encubrir una intención patológica por falsa, caprichosa o ajena a los requerimientos del puesto o a las exigencias de idoneidad profesional que llevaron a la elección. Esta exigencia de motivación se cualifica cuando se trata del cese de quien ejerce funciones de representación sindical.

Sentada esta doctrina y casada la sentencia de la Audiencia Nacional recurrida, el Tribunal Supremo estima la demanda del recurso contencioso-administrativo, aunque solo en parte. Anula, ciertamente, el cese; pero condena al Consejo de Seguridad Nuclear simplemente a que dicte un nuevo acto en el que exponga la causa de ese cese para satisfacer el derecho del demandante a conocerla. Por el contrario, desestima la pretensión de este de que se le reponga en el puesto, ya que no tiene un derecho a la permanencia en él, así como su pretensión de resarcimiento. Pues, en realidad, el Tribunal Supremo no cuestiona que pudieran o no existir en el caso razones válidas para el cese, sino que no se han expresado. 
La nueva jurisprudencia ahora establecida es, pues, muy matizada. Ni el nombramiento por libre designación garantiza al funcionario el desempeño ilimitado del puesto, aunque cumpla correctamente sus funciones, ni la decisión de cese deja de ser un acto discrecional, en la medida en que se reconoce al órgano competente un margen de apreciación para adoptarlo. Sin embargo, es necesario que existan razones objetivas o de interés general para la remoción del cargo, basadas siempre en circunstancias de índole profesional, que justifiquen la pérdida de la confianza — asimismo profesional y no personal— que determinó en su día el nombramiento. Pues es obvio que esas circunstancias pueden cambiar por múltiples causas, unas ajenas a la voluntad del interesado, como, por ejemplo, la aparición de nuevas exigencias o requerimientos para el desempeño del puesto, y otras no tanto, como su propio comportamiento, dedicación, nivel de compromiso, etc. Y esos motivos reales que pueden justificar el cese deben quedar suficientemente expuestos. Tanto en favor del funcionario cesado, que tiene derecho a conocerlos, como para hacer posible el control judicial de la conformidad a derecho de la decisión o, lo que es igual, del respeto a los límites de la discrecionalidad. Lo que la nueva jurisprudencia impone es, ante todo, un deber de transparencia para verificar si el margen de apreciación propio de la facultad de cese en estos puestos se utiliza o no conforme al interés público y respetando la igualdad y los legítimos intereses de los funcionarios.

Pues lo que pretende el Tribunal Supremo con ello es, como viene a indicar, evitar la patología que supone el cese de funcionarios en puestos de libre designación por causas puramente ideológicas o por la mera voluntad o capricho de la autoridad competente, ligada a vínculos personales. Lo cual, debe añadirse, es ya mucho, dado que no es nada infrecuente en muchas Administraciones públicas que un alto porcentaje de los funcionarios que desempeñan cargos de libre designación, por ejemplo, del nivel de los subdirectores generales o equivalentes, sean sustituidos cuando se constituye un nuevo gobierno - estatal, autonómico o local, da igual — por la simple razón (aún no explicitada) de que fueron nombrados por otro gobierno anterior de distinto signo.

\section{ALGUNAS CONCLUSIONES, MIRANDO AL FUTURO}

En pocos años, de la manera que resumidamente se ha pretendido explicar aquí, el Tribunal Supremo, con aportaciones de otros tribunales, ha cambiado la concepción jurídica del procedimiento de libre designación para la provisión de destinos en la función pública. Lo ha hecho en sintonía con el impulso de renovación que inspiró la reforma del régimen básico del empleo público en 2007 — aunque solo fuera asumido tímidamente por el legislador-, con el modelo altamente profesionalizado de empleo público que rige en la mayoría de los Estados de nuestro entorno europeo y creo que también con la tendencia dominante en nuestra sociedad, cansada ya de contemplar tantos ascensos (y descensos) fulgu- 
rantes en el desempeño de cargos públicos, ligados a la mera voluntad subjetiva de los gobernantes.

Con la nueva doctrina jurisprudencial, los nombramientos y ceses de funcionarios en puestos de libre designación han quedado jurídicamente excluidos de ese sistema que fue definido en el pasado como el de "confianza política», que ha regido hasta ahora en el ámbito de nuestra función pública superior. Inclusive bajo el régimen constitucional, porque así lo quisieron los legisladores o, si se prefiere, los partidos políticos con representación parlamentaria, en el Estado y en las comunidades autónomas. Confianza que, en realidad, no solo depende de afinidades "políticas» o ideológicas, sino que muchas veces es puramente personal. La presencia o ausencia de este tipo de confianza ya no es motivo que pueda contar para cubrir ese tipo de puestos, pues debe quedar confinada a aquellos otros que son propiamente de gobierno y, si acaso, otros altos cargos -al menos mientras no se desarrolle el estatuto del personal directivo también previsto en el $\mathrm{EBEP}^{23}$ — , además del llamado personal eventual, que realiza funciones de confianza o asesoramiento especial y cuyo nombramiento y cese son, efectivamente, libres $^{24}$.

Ahora bien, una cosa es que haya mutado la naturaleza jurídica de la provisión de puestos de funcionarios por la — mal llamada ya — «libre» designación y otra cosa es que ese cambio tenga reflejo cierto en la realidad de nuestras diferentes Administraciones públicas. La nueva doctrina alumbrada por la jurisprudencia chocará, sin duda, con una fuerte inercia en pro de dejar las cosas como están, alimentada por la concepción del ejercicio del poder público que siguen sosteniendo de manera expresa o tácita gran parte de los gobernantes y de los altos cargos de designación política. En la práctica, las reformas en el régimen de la función pública suelen ser complejas y lentas, incluso si obedecen a la aprobación de normas de contenido claro y terminante - lo que no es, por cierto, el caso de muchas de las incluidas en el EBEP — o a la jurisprudencia de los tribunales. Pues la burocracia pública es un mundo muy imperfecto y conflictivo, en el que

23 Pues cabe recordar que el art. 13 del EBEP, que sigue en vigor, prevé también la designación de ese personal directivo conforme a principios de mérito y capacidad y criterios de idoneidad y mediante procedimientos que garanticen la publicidad y la concurrencia. El escasísimo desarrollo de este precepto, que ni siquiera afecta a los altos cargos no gubernativos de las distintas Administraciones - lo que singulariza lamentablemente a nuestro país en el marco de los de Europa occidental-, es una muestra palpable más de la concepción patrimonialista del poder que mantienen nuestros partidos políticos. Pero sobre esta cuestión no procede extenderse ahora.

24 Este personal eventual es, en efecto, un grupo aparte de la función pública en sentido propio. Aunque retribuido con cargo a los presupuestos públicos, se diría que son más bien empleados de quienes lo nombran, a cuyo exclusivo servicio están, y no de la Administración pública como institución que gestiona con objetividad los intereses generales. Sobre ello, S. Fernández Ramos (2013), «Los falsos empleados públicos: el personal eventual», Revista General de Derecho Administrativo, 34. 
confluyen intereses variados, que de una u otra forma procuran encontrar su forma de expresión.

$\mathrm{Si}$, como es de esperar, la nueva línea jurisprudencial se consolida, y si es asumida con convicción por los jueces y tribunales inferiores, en los que va a recaer la tarea de aplicarla, es muy posible que se multipliquen los recursos contra nombramientos y ceses, pues muchos de ellos no se motivan hoy en día y otros se acompañan de una motivación retórica o formal, de esas que el Tribunal Supremo denomina "estandarizadas». Tampoco será fácil en muchas ocasiones ejercer un control efectivo de las decisiones que al respecto se impugnen, pues, como se ha dicho, siempre cabe respetar un margen de libre apreciación en favor de las autoridades competentes y eso es razonable, tratándose de nombramientos para puestos de responsabilidad, que no se deben resolver mediante la aplicación mecánica de un baremo. Dichas autoridades, sin embargo, harían bien en basar su apreciación de la idoneidad de los candidatos en informes previos sobre sus currículums o, como se propuso en su día, en el criterio de especialistas o comisiones por ellos compuestas.

Lo que está claro es que la ausencia de motivación o una motivación solo aparente o incoherente puede dar lugar a partir de ahora, con alta probabilidad, a una sentencia anulatoria del nombramiento o del cese, en caso de recurso. Eso sí, no siempre podrán los jueces y tribunales adoptar un fallo de nulidad por razones de fondo, esto es, declarando la falta de idoneidad de un nombramiento ${ }^{25}$ o la manifiesta improcedencia de un cese, salvo prueba suficiente al efecto, sino que, como se ha podido ver, con frecuencia no tendrán otra alternativa que condenar a la Administración a que aporte una motivación real y suficiente de lo que acuerde en definitiva. Pero de la ausencia o incoherencia de la motivación también podría deducirse en ciertos supuestos la existencia de una infracción sustantiva de los principios de igualdad, mérito y capacidad o el vicio de desviación de poder.

Dicho lo cual, el giro que desde hace unos años ha iniciado la jurisprudencia de la Sala de lo Contencioso-Administrativo del Tribunal Supremo para acotar la discrecionalidad en materia de selección y provisión —así como de remociónde puestos de trabajo en la función pública y controlar su ejercicio, es una contribución importante para garantizar la aplicación de los principios del Estado de derecho en el seno mismo de la Administración pública. Las últimas sentencias

25 Y menos aún disponer quién debería ser nombrado en sustitución del que lo fue ilegalmente, aunque puede adoptarse esa decisión judicial si es la única aceptable en derecho, en supuestos peculiares de reducción de la discrecionalidad auf null. Véase, por ejemplo, el caso examinado por la STS de 19 de octubre de 2009 (rec. 58/2007), que confirma otra de la Sala de Albacete en apelación de la de un Juzgado de lo Contencioso-Administrativo de Ciudad Real sobre nombramiento para el cargo de secretario general de la Diputación de Ciudad Real. Declarada ilegal por falta de motivación del nombramiento en favor de uno de los dos únicos candidatos y advertida por el juzgado la existencia de desviación de poder, se declara que debe ser la otra candidata la que debe ser designada para el puesto, pronunciamiento que ni la Sala de apelación ni el Tribunal Supremo revocan. 
dictadas sobre la cuestión en el año 2019, de las que hemos dado cuenta, son un paso adelante más. Como en otras materias, la «formación de jurisprudencia» que corresponde al Alto Tribunal a través del recurso de casación supone en esta un verdadero ejercicio de creación del derecho. Y ello debe valorarse en su justa medida. Máxime si se considera la situación de apatía, falta de voluntad reformista o, sencillamente, incomparecencia que nuestros legisladores vienen demostrando últimamente. 
